\title{
Protective Effects of $\alpha$-Tocopherol against Brain Tissue Damage Induced by Intracerebral Hemorrhage in SD Rats
}

\author{
Zhiyong Chen, Jinfu Yang*, Fuyin Ren, Weiwei Ye, Guangyong Wu \\ Department of Neurosurgery, The Third Xiangya Hospital of Central South University, Changsha, China \\ Email: "sjwkyjf@hotmail.com
}

Received 18 January 2016; accepted 26 February 2016; published 29 February 2016

Copyright (C) 2016 by authors and Scientific Research Publishing Inc.

This work is licensed under the Creative Commons Attribution International License (CC BY). http://creativecommons.org/licenses/by/4.0/

(c) (7) Open Access

\section{Abstract}

Lipid peroxidation mediated by oxygen radical is one of the main mechanisms underlying secondary brain injury. Among all vitamin E compounds, $\alpha$-tocopherol shows the most prominent antioxidative effects. It plays an important role in cell aging and injury. However, there has been no report regarding the effects of $\alpha$-tocopherol on changes in brain tissue morphology after intracerebral hemorrhage (ICH), cerebral edema, or the expression of Bax and Bcl-2 proteins. We use SD rats to carry out the related studies; based on the atlas of SD rats, the caudate nucleus was positioned using a stereotaxic apparatus, and $50 \mu \mathrm{l}$ autologous tail artery blood was injected to caudate nucleus in the ICH and $\alpha$-tocopherol groups to establish ICH model. Rats in the sham surgery group received the same volume of saline in the caudate nucleus. Rats in the $\alpha$-tocopherol group received intraperitoneal injections of $\alpha$-tocopherol at $600 \mathrm{mg} / \mathrm{kg}$ every day. Rats in the ICH group and sham surgery group received the same amount of saline at the same times as those in the $\alpha$-tocopherol group. We observed some interesting results: comparisons of brain tissue sections of rats from different groups showed that brain tissue damage and functional neurological deficits among rats from the $\alpha$-tocopherol group were less pronounced than in the ICH group. Wet weight/ dry weight measurement showed that rats from the $\alpha$-tocopherol group exhibited less cerebral edema than those in the ICH group. Rats from the $\alpha$-tocopherol group showed less Bax expression and more Bcl-2 expression than those in the ICH group.

\section{Keywords}

$\alpha$-Tocopherol, Intracerebral Hemorrhage (ICH), Cerebral Edema, Bax, Bcl-2

\footnotetext{
${ }^{*}$ Corresponding author.
}

How to cite this paper: Chen, Z.Y., Yang, J.F., Ren, F.Y., Ye, W.W. and Wu, G.Y. (2016) Protective Effects of $\alpha$-Tocopherol against Brain Tissue Damage Induced by Intracerebral Hemorrhage in SD Rats. World Journal of Neuroscience, 6, 62-74. 


\section{Introduction}

ICH is a type of stroke. It accounts for $17.1 \%-55.4 \%$ of all strokes in China [1]. This is far higher than the $6.5 \%$ - 19.6\% in Western countries [2]-[4]. Common causes of ICH include hypertension, cerebral arteriosclerosis, and cerebrovascular malformation, with the former two being the leading causes [5]-[7]. In recent years, there have also been cases of ICH caused by long-term use of anticoagulants such as warfarin and aspirin [8] [9]. ICH has become a severe cerebral complication. It occurs frequently in middle-aged and elderly patients with hypertension. Due to its acute onset and fast progression, the mortality rate of ICH has remained high, and it poses a severe threat to the health of middle-aged and elderly individuals.

Currently, clinical treatment for ICH mainly involves selective surgery or non-operative treatment, as indicated by the size of the hematoma and the overall condition of the patient. Most surgeries for removal of the hematoma are minimally invasive [10] [11]. Non-operative treatments include lowering blood pressure, stopping bleeding, maintaining the internal environment, and symptomatic therapy and support. However, none of these methods are entirely satisfactory [12]-[14]. Damaged neural cells and neurological functions do not recover well [15] [16]. Studies on the treatment and prevention of ICH have been performed both in China and in other countries. Most of these have been drug studies, and there has not been much success.

After ICH, there appears a penumbra surrounding the hematoma and a drop in local blood flow. This can lead to global cerebral ischemic damage [17]-[19]. Ischemia and hypoxia can cause irreversible damage to neurons. There is also secondary brain damage, such as neuronal damage caused by free radicals, neuronal apoptosis and death, and damage caused by inflammatory cells. Of these, cell apoptosis has been subjected to the most study [20] [21]. After ICH, all neurons in the center area of the hematoma die, and neurons in the surrounding areas suffer from ischemia and hypoxia, due to the increased pressure caused by hematoma. Cerebral edema and the various destructive factors released initiate apoptosis among neurons. This plays an important role in secondary brain damage [22]-[24]. Effective methods of intervening in this process are important to the prognosis of these patients.

$\alpha$-tocopherol is a type of vitamin E. It includes four tocopherols and four tocotrienols $(\alpha, \beta, \gamma, \delta)$. All vitamin E compounds have a chroman ring, but their isoprenoid side-chains are different [25]-[28]. Many researchers reported that vitamin $\mathrm{E}$ compounds not only regulate endocrine responses and promote reproductive function but also exhibit antioxidative effects, especially $\alpha$-tocopherol [29]-[31]. Studies have shown that $\alpha$-tocopherol can reduce the extracellular concentration of oxygen free radicals. Due to its lipid solubility, it can pass through the cell membrane and reduce the intracellular concentration of oxygen free radicals, alleviating damage to cells [32]-[34]. In 2005 it was reported that $\alpha$-tocopherol can prevent oxygen free radicals from attacking the proteins and unsaturated fatty acids in the cell membrane, preserving the basic function of cell membrane [35].

In the current experiment, autologous tail artery blood was injected into the caudate nuclear region with a stereotaxic apparatus to establish animal models for ICH. Functional neurological deficits, changes in brain tissue morphology, changes in brain tissue water content, and changes in the expression of two apoptosis-related proteins Bax and Bcl-2, were observed after $\alpha$-tocopherol intervention. In order to determine the protective effects of $\alpha$-tocopherol on the rat nervous system and underlying mechanisms and provide a theoretical basis for the clinical use of $\alpha$-tocopherol.

\section{Materials and Methods}

\subsection{Experimental Animals}

Healthy male Sprague Dawley (SD) rats provided by the Laboratory Animal Center, Xiangya School of Medicine, Central South University, weighing 250 - 270 g, were used. (Thirty died during the experiment and the model was not successfully established in 6 . These animals were replaced with new ones. The total number of rats used was 180.) All experimental procedures were approved by the Medical Ethic Committee, the Third Xiangya Hospital, Central South University. All rats were reared at 3rats/cage with standard rat feed mixture and water ad libitum. During the experiments, rats were kept at room temperature $20^{\circ} \mathrm{C}-25^{\circ} \mathrm{C}$ and humidity above 50\%. Air inside and outside the room was kept clean and ventilated, and the rats were allowed free activity in the cage. Animals were randomly divided into three groups based on a random number table: the sham surgery group $(n=48)$, the ICH group $(n=48)$ and the $\alpha$-tocopherol group $(n=48)$. Based on the time at which the animals were killed, rats in each group were further divided into 4 subgroups, 6 h, $1 \mathrm{~d}, 3 \mathrm{~d}$, and $7 \mathrm{~d}$ sub- 
groups. Each subgroup contained 12 rats, among which 6 were used for measurement of brain tissue water content, and 6 were used for immunohistochemical testing.

These experiments were conducted in a double-blind conditions, including observation of HE and immunohistochemical microscope, nerve function score. We only identify the number of animal and specimen, evaluators do not know grouping situation.

\subsection{Establishment of the Animal Models}

Rats were fasted for 8 hours before surgery and given free access to water. The method used to establish the autologous blood ICH model was similar to that described by Rosenberg et al. [36], in which collagenase was injected into the caudate nucleus. Specifically, the SD rat was first subjected to intraperitoneal anesthesia with $10 \%$ chloral hydrate ( $3 \mathrm{mg} / \mathrm{kg}$ body weight). It was then fixated in a stereotax according to the method reported by Paxinos, G et al. [37]. The interaural plane was about $2.4 \mathrm{~mm}$ higher than the maxillary plane, and the anterior and posterior fontanels were positioned in the same plane to the greatest extent possible. Iodine and $75 \%$ alcohol were applied for local sterilization, and a $1-2 \mathrm{~cm}$ incision was made at the center of the scalp. The periosteum was cut open and isolated using surgical scissors to expose the anterior fontanel. At about $4.0 \mathrm{~mm}$ to the left along the sagittal line and about $0.2 \mathrm{~mm}$ anterior to the anterior fontanel, a hole was carefully drilled through the skull with a dental drill. Care was taken not to penetrate the dura or damage the brain tissue. A 100 $\mu \mathrm{l}$ microsyringe was used to collect $50 \mu \mathrm{l}$ unclotted blood from the rats' tails, which had been soaked in warm boiled water at $40^{\circ} \mathrm{C}$ for $10 \mathrm{~min}$. Tails were punctured $1 / 3$ to the end for blood collection. The syringe was inserted vertically into the hole on skull about $6 \mathrm{~mm}$ downward (corresponding to the left caudate nucleus); blood was slowly injected (over the course of about $3 \mathrm{~min}$ ) and the microsyringe remained inserted for another $10 \mathrm{~min}$ before retraction. At the end of the surgery, bleeding was stopped completely, and the incision was sutured after sterilization with $75 \%$ alcohol. Rats in the sham surgery group received the same surgery, excepting that $50 \mu 1$ saline instead of autologous tail artery blood was injected into the caudate nucleus. After surgery, the animal was transferred to a normal room at room temperature for recovery.

Evaluation of the establishment of the model: After the rats woke up, their neurological deficits were evaluated using Bederson neurological deficit scores [38]. When normal rats are lifted gently by the tail to a height about $10 \mathrm{~cm}$ above table level, their front paws are extended. Score 0: normal activity, no deficit; Score 1: When the tail is lifted, the right front limb of the rat is bent, shoulder adducted and bent; Score 2: The rat's resistance to lateral thrust force is reduced, accompanied by bent right front limb, adducted and bent shoulder; Score 3: During activity, the rat circles toward the paralyzed direction, accompanied by the symptoms listed for score 2 . All rats from the sham surgery group were selected for further experiments. In the ICH and treatment groups, only animals that had neurological deficit scores higher than 2 were selected. The criteria used to exclude ICH model rats also included backflow along the needle track, subarachnoid hemorrhage, lack of hematoma on the brain tissue section, death during surgery, or loss of consciousness or death after surgery.

\subsection{Post-Surgical Evaluation of the Rats' Neurological States}

Using mNSS developed by Schallert et al. [39], movement, sense, balance, and reflex were tested in the rats from all three groups. The lowest score was 0 , which represents normal neurological function; the highest score was 18. Higher scores represent more severe damage to neurological function (Table 1 NSS). This evaluation was performed at the four designated points in time after surgery.

\subsection{Sample Collection and Processing}

Collection of fresh brain tissues: At the designated time points after surgery (6 h, $1 \mathrm{~d}, 3 \mathrm{~d}, 7 \mathrm{~d}$ ), rats in the three groups were evaluated using mNSS assessment. They were then subjected to intraperitoneal anesthesia using $10 \%$ chloral hydrate, followed by decapitation with surgical scissors. The whole brains were removed using surgical forceps, and $4^{\circ} \mathrm{C}$ cold saline was used to rinse off residual blood in the brain tissue, which was then dried with filter paper. The olfactory bulb, cerebellum, and lower brainstem were removed and discarded, and the brain tissues were stored at $-86^{\circ} \mathrm{C}$ for further use.

Collection of samples for immunohistochemistry testing: At the designated points in time points after surgery ( 6 h, $1 \mathrm{~d}, 3 \mathrm{~d}, 7 \mathrm{~d}$ ), rats in all three groups were subjected to intraperitoneal anesthesia using $10 \%$ chloral hydrate. 
Table 1. Neurological Severity Scores (NSS).

\section{Points $^{*}$}

Motor tests

Raising rat by the tail

1 Flexion of forelimb

1 Flexion of hindlimb

1 Head moved $>10^{\circ}$ to vertical axis within $30 \mathrm{~s}$

Placing rat on the floor (normal $=0$; maximum $=3$ )

0 Normal walk

1 Inability to walk straight

2 Circling toward the paretic side

3 Fall down to the paretic side

Sensory tests

1 Placing test (visual and tactile test)

2 Proprioceptive test

(deep sensation, pushing the paw against the table edge to stimulate limb muscles)

Beam balance tests (normal $=0$; maximum $=6$ )

0 Balances with steady posture

1 Grasps side of beam

2 Hugs the beam and one limb falls down from the beam

3 Hugs the beam and two limbs fall down from the beam, or spins on beam(>60 s)

4 Attempts to balance on the beam but falls off ( $>40 \mathrm{~s}$ )

5 Attempts to balance on the beam but falls off (>20 s)

6 Falls off: No attempt to balance or hang on to the beam $(<20 \mathrm{~s})$

Reflexes absent and abnormal movements

1 Pinna reflex (head shake when touching the auditory meatus)

1 Corneal reflex (eye blink when lightly touching the cornea with cotton)

1 Startle reflex (motor response to a brief noise from snapping a clipboard paper)

Seizures, myoclonus, myodystony Maximum points

18

Footnote: One point is awarded for the inability to perform the tasks or for the lack of a tested reflex; 13 to 18 points indicate severe injury; 7 to 12 points indicate moderate injury; 1 to 6 points indicate mild injury.

A transverse incision was made below the xiphisternum, and the diaphragm was cut open along the boundary between the diaphragm and the thorax to fully expose the heart. A needle was inserted into the cardiac apex, upward through the left ventricle, reaching the aorta. With the needle secured by one hand, the right atrium was cut open with surgical scissors, and a large syringe $(50 \mathrm{ml})$ was used to rapidly inject $200-400 \mathrm{ml} 4^{\circ} \mathrm{C}$ cold saline. When the fluid flowing out became clear, $4^{\circ} \mathrm{C} 4 \%$ paraformaldehyde in PBS was injected. After a period of time, the four limbs of the rat started to twitch, the tail and the body became relatively stiff, and the liver turned pale. At this point perfusion was stopped, and surgical clamps and scissors were used decapitate the rat and remove its brain, which was first fixated in $4 \%$ paraformaldehyde for one day, then stored in tissue preservation solution for further use. 


\subsection{Immunohistochemical Tests of Bax and Bcl-2}

Dewaxed brain tissue slides were placed in citrate buffer (0.01 M pH 6.0) to boil. After cooling at room temperature, slides were rinsed three times with PBS buffer, then incubated in 3\% $\mathrm{H} 2 \mathrm{O} 2$ solution (to block to block endogenous peroxidase) at $37^{\circ} \mathrm{C}$ for $20 \mathrm{~min}$, followed by three rinses with PBS buffer. The slides were incubated with Bax and Bcl-2 antibodies (1:150) in a $4^{\circ} \mathrm{C}$ refrigerator overnight. After rinsing with PBS buffer, corresponding anti-rabbit secondary antibody solution (1:400) was added for incubation at $37^{\circ} \mathrm{C}$ for $30 \mathrm{~min}$. Then HRP-labeled streptomycin avidin working solution was added for incubation at $37^{\circ} \mathrm{C}$ for 30 min. The slides were subjected to DAB staining, hematoxylin counterstaining, and mounted with neutral resins after serial dehydration. They were then dried and subjected to microscopic examination.

All brain tissues were sectioned coronally, with the needle track at the center. The slides were observed under $\times 10, \times 20$, and $\times 40$ objective lenses, respectively. The positive cells were counted under the same illumination intensity (4.0) and a $\times 400$ lens. For each rat, 3 coronal slides of brain tissue taken from the same location were used, and the positive cells were counted in 4 non-overlapping fields. The mean was calculated and used as the number of positive cells.

\subsection{Quantitative Real-Time PCR}

Extraction of total RNA of whole cerebrum and qRT-PCR were performed as described previously [40]. The following were the sequences of primers: for Bcl-2:5'-ACTTTGCAGAGATGT CCAGTC AG-3' and 5'-GTTCAGGTACTCAGTCATCCACAG-3'; for bax: 5'-GGA GGAAGTCCAGTGTCCAG-3' and 5'-TGCAGAGGATGATTGCTGAC-3'; and for GAPDH:5'-ACCACAGTCCATGCCATCAC-3' and 5'-TCCACCACCCTGTTGCTGTA-3'. The 2- $\triangle \mathrm{CT}$ method was used to assess the relative expression of target genes and the final data were described as fold changes against control tissues.

\subsection{Measurement of the Water Content of Brain Tissues}

The wet weight/dry weight method was used to measure the water content of the brain tissues collected from the experimental animals. The left and right hemispheres of the harvested brains were cut into and their wet weights were measured (accuracy $0.1 \mathrm{mg}$ ). Then the brain tissues were dried in an oven at $100^{\circ} \mathrm{C}$ for about 24 hours. They were weighed repeatedly until the measurement remained the same. Water content of brain tissue $=[$ (wet weight of the brain tissue-dry weight of the brain tissue)/wet weight of the brain tissue] $\times 100 \%$.

\subsection{Statistical Analysis}

After these experiments, all data were analyzed using SAS statistical software (SAS ver. 9.2; SAS Institute Inc; North Carolina, USA). All data are represented as mean \pm standard deviation. For multiple comparisons between the groups was performed using ANOVA and LSD testing, comparison between left and right hemisphere was analyzed using paired-t test. At $P<0.05$, the difference was considered statistically significant.

\section{Results}

\subsection{HE Staining}

Pathological testing showed that, in rats from the sham surgery group, the brain tissues nearest the needle track exhibited only minor damage, and there was no notable change in cell arrangement (Figure 1(I)). In rats from the ICH group, a large number of red blood cells were observed surrounding the hematoma. Inside the hematoma, there was serious brain tissue necrosis and substantial neural cell loss. Large vesicular regions were observed around the hematoma, indicative of severe cerebral edema; infiltration of inflammatory cells was also notable. Rats from the $\alpha$-tocopherol group showed less damage to the neural cells and less infiltration of inflammatory cells than those in the ICH group. In rats from the ICH group, at $6 \mathrm{~h}$, the neurons were swelling visibly, and edema had begun started. At $1 \mathrm{~d}$, edema became notable, and there was some neural cell loss; staining was light, and the cell bodies were smaller than normal with increased intercellular space. The cell nuclei were deformed, and the nucleoli were barely visible. At $3 \mathrm{~d}$, in the area where the edema was severe, the neural cells had shrunk in volume, and the brain tissue had become loose. Foam cells appeared, accompanied by karyopyknosis, loss of Nissl bodies, and infiltration of inflammatory cells such as neutrophil granulocytes and lympho- 
cytes. At 7 d, the brain tissue edema had become somewhat alleviated, showing reduced neural cell swelling and fewer inflammatory cells. The number of macrophages had increased, and overgrowth of glial cells and fibrous tissue was visible (Figures 1(a)-(d)). In rats from the $\alpha$-tocopherol group the edema was less severe at every point in time, and there were fewer inflammatory cells and less neural cell necrosis (Figures 1(e)-(h)).

\subsection{Result of Evaluation on Neurological Function}

In rats in the sham surgery group, damages to the surrounding brain tissues during the saline injection procedure caused some short-term functional neurological deficits after waking. They had recovered by $3 \mathrm{~d}$. Rats in the ICH group however, influenced by hematoma, exhibited abnormal neurological function and losses of different degrees in movement, sense, balance, and reflexes. The mNSS score was relatively high, and the conditions were most severe at $3 \mathrm{~d}$. This was significantly different from rats in the sham surgery group (Table $2 P<0.01$ ). Rats in the $\alpha$-tocopherol group showed less pronounced deficits in movement, sense, balance, and reflexes and a significantly lower mNSS scores than ICH rats (Table $2 P<0.05$ ).

\subsection{Changes in the Water Content of Brain Tissues Following ICH}

Cerebral edema started 6 hours after ICH and peaked on 3 - 7 d. At 6 h, 1d, 3d, and 7d, rats in the ICH group exhibited greater brain tissue water content than rats in the sham surgery group, and the difference was statistically significant (Table $3,{ }^{*} P<0.05$ ). Rats in the $\alpha$-tocopherol group showed significantly less cerebral edema on the surgical side and significantly less water content than rats in the ICH group (Table $3,{ }^{\#} P<0.01$ ). When comparing the two hemispheres, only rats in the ICH model group showed significantly different levels of brain tissue water content (Table $3,{ }^{\mathbf{\Delta}} P<0.05$ ).

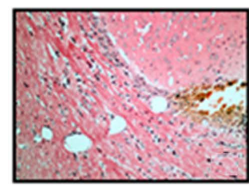

(a)

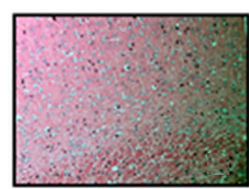

(e)

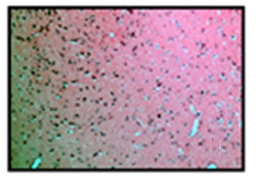

(i)

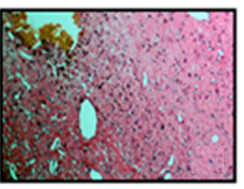

(b)

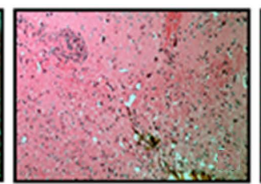

(f)

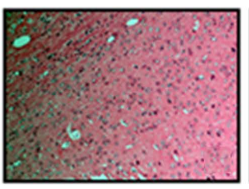

(c)

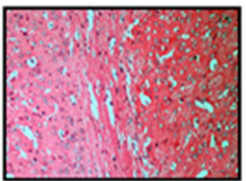

(g)

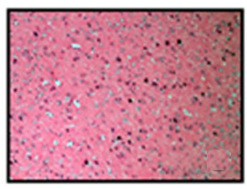

(d)

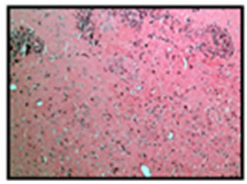

(h)

Figure 1. Microscopic examination of HE stained rat brain tissue. Figure Labels: All sections were observed under the same illumination intensity (4.0) and a ×200 lens. (a)-(d): the ICH group 6 h, $1 \mathrm{~d}, 3 \mathrm{~d}, 7 \mathrm{~d}$; (e)-(h): the $\alpha$-tocopherol group 6 h, $1 \mathrm{~d}$, $3 \mathrm{~d}, 7 \mathrm{~d}$; (i): the sham surgery group.

Table 2. Neurological severity scores of rats.

\begin{tabular}{ccccc}
\hline Group & $6 \mathrm{~h}$ & $1 \mathrm{~d}$ & $3 \mathrm{~d}$ & $0.0 \pm 0^{*}$ \\
\hline Sham surgery group & $1.8 \pm 0.7^{*}$ & $0.6 \pm 0.5^{*}$ & $0 \pm 0^{*}$ & $9.2 \pm 1.9$ \\
ICH group & $7.3 \pm 1.3$ & $10.3 \pm 2.1$ & $9.5 \pm 2.6$ & $9.7 \pm 1.4^{* \#}$ \\
$\alpha$-tocopherol group & $6.1 \pm 1.4^{* \#}$ & $7.9 \pm 1.8^{* \#}$ & 174.16 & $<.5 \pm 1.8^{* \#}$ \\
F value & 70.14 & 118.6 & $<0.01$ & $<1.15$ \\
P value & $<0.01$ & $<0.01$ & $<0.01$ \\
\hline
\end{tabular}

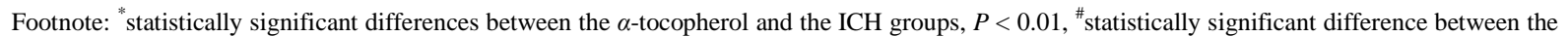
$\alpha$-tocopherol and the sham surgery groups, $P<0.01$. 
Table 3. Water content of rat brain tissues $(n=6)$.

\begin{tabular}{|c|c|c|c|}
\hline Time points & Group & Left hemisphere (surgical side) & Right hemisphere \\
\hline \multirow{3}{*}{$6 \mathrm{~h}$} & Sham surgery group & $71.3 \pm 0.3$ & $71.3 \pm 0.6$ \\
\hline & ICH group & $75.5 \pm 0.4^{*}$ & $74.2 \pm 0.3^{\mathbf{\Lambda}}$ \\
\hline & $\alpha$-tocopherol group & $73.4 \pm 0.4^{\#}$ & $73.4 \pm 0.3$ \\
\hline \multirow{3}{*}{$1 d$} & Sham surgery group & $71.4 \pm 0.5$ & $71.4 \pm 0.4$ \\
\hline & ICH group & $77.6 \pm 0.4^{*}$ & $75.5 \pm 0.4^{\mathbf{4}}$ \\
\hline & $\alpha$-tocopherol group & $73.1 \pm 0.5^{\#}$ & $73.5 \pm 0.5$ \\
\hline \multirow{3}{*}{ 3d } & Sham surgery group & $71.5 \pm 0.8$ & $71.4 \pm 0.5$ \\
\hline & ICH group & $80.6 \pm 0.4^{*}$ & $77.7 \pm 0.4^{\mathbf{\Lambda}}$ \\
\hline & $\alpha$-tocopherol group & $73.5 \pm 0.4^{\#}$ & $73.6 \pm 0.3$ \\
\hline \multirow{3}{*}{$7 d$} & Sham surgery group & $71.3 \pm 0.4$ & $71.4 \pm 0.8$ \\
\hline & ICH group & $79.5 \pm 0.2^{*}$ & $76.6 \pm 0.5^{\mathbf{A}}$ \\
\hline & $\alpha$-tocopherol group & $73.7 \pm 0.3^{\#}$ & $73.3 \pm 0.1$ \\
\hline
\end{tabular}

Footnote: Water content of brain tissue $=[$ (wet weight of the brain tissue-dry weight of the brain tissue $) /$ wet weight of the brain tissue $] \times 100 \%$. ${ }^{*}$ Rats in the ICH group showed significantly more brain tissue water content than rats in the sham surgery group $P<0.01$; \# Rats in the $\alpha$-tocopherol group showed significantly less brain tissue water content than rats in the ICH group, $P<0.01$; ${ }^{\mathbf{\Lambda}}$ When comparing the two hemispheres of rats in the ICH group, the water content of brain tissue from the left hemisphere, the surgical side, was significantly higher, $P<0.05$.

\subsection{Changes in Bax Expression in Rat Brain Tissues}

Bax-positive cells were observed in brain tissues surrounding the hematoma. Most Bax was expressed in the cytoplasm, some in the cell membrane. Bax was stained mostly brown, and the overall outline of the cells was readily visible. In the brains of rats from the sham surgery group, only a small amount of Bax positive expression was observable and only near the needle track, not elsewhere. In rats from the ICH group, Bax expression started at $6 \mathrm{~h}$, peaking at $1 \mathrm{~d}$, after which it started to decrease. At $7 \mathrm{~d}$, a small amount of Bax expression was still observable (Figures 2(a)-(d)). Bax expression in the brain tissue of rats from the $\alpha$-tocopherol group were significantly lower than in the ICH model group at all corresponding points in time (Table 4, $P<0.05$; Figures 2(e)-(h)). Results of real time PCR showed that the expression of Bax in $\alpha$-tocopherol-treated rats were lower than that of ICH group (Figure 3).

\subsection{Changes in Bcl-2 Expression in Rat Brain Tissue}

Bcl-2 expression was mainly observed in the cytoplasm and the cell membrane. It was mostly stained brown. The expression was concentrated in brain tissues surrounding the hematoma, and the overall outline of the cells was visible. In rats from the sham surgery group, a small amount of Bcl-2 expression was observed near the needle track. In rats from the ICH group, Bcl-2 expression started at $6 \mathrm{~h}$ and gradually increased after $1 \mathrm{~d}$, peaking at $3 \mathrm{~d}$. At $7 \mathrm{~d}$, Bcl-2 expression had started to decrease (Figures 4(a)-(d)). Rats in the $\alpha$-tocopherol group showed significantly more Bcl-2 expression than rats in the ICH group (Table 5, \# $P<0.05$; Figures 4(e)-(h)). Results of real time PCR showed that the expression of Bcl-2 in $\alpha$-tocopherol-treated rats at $3 \mathrm{~d}$ and $7 \mathrm{~d}$ were higher than that of ICH group (Figure 5).

\section{Discussion}

Animal experiments have demonstrated that when ICH occurs, edema forms, and the neurological functions of the rats are influenced to different extents. As time passes, ischemia and hypoxia start near the hematoma, and vasoactive substances and free radicals are released, inducing a series of changes, such as lipid peroxidation and cell apoptosis. Multiple destructive substances are released during hematoma absorption. All these aggravate damage to the neurological functions [41] [42]. In the current study, at $6 \mathrm{~h}$, partial functional neurological deficit 


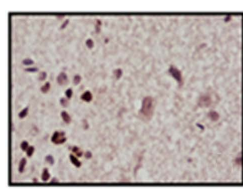

(a)

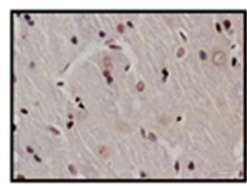

(e)

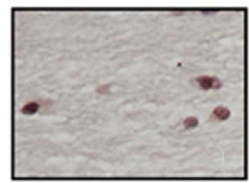

(i)

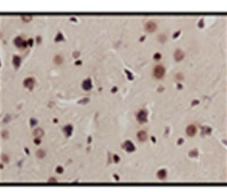

(b)

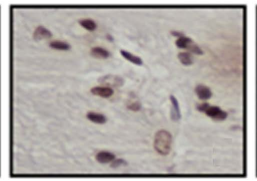

(f)

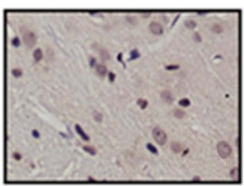

(c)

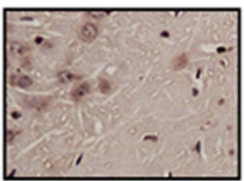

(g)

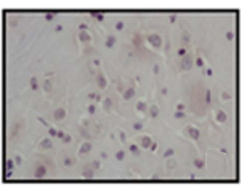

(d)

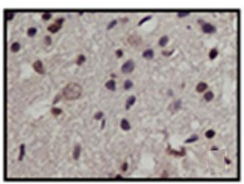

(h)

Figure 2. Bax expression in rat brain tissue. Figure Labels: All sections were observed under the same illumination intensity (4.0) and a $\times 400$ lens. (a)-(d): Bax positive staining in rat brain tissues; 6 h, $1 \mathrm{~d}, 3 \mathrm{~d}, 7 \mathrm{~d}$; ICH group. (e)-(h): Bax positive staining in rat brain tissues; 6 h, 1 d, 3 d, 7 d; $\alpha$-tocopherol group. (i): Bax positive staining in rat brain tissues, Sham surgery group.

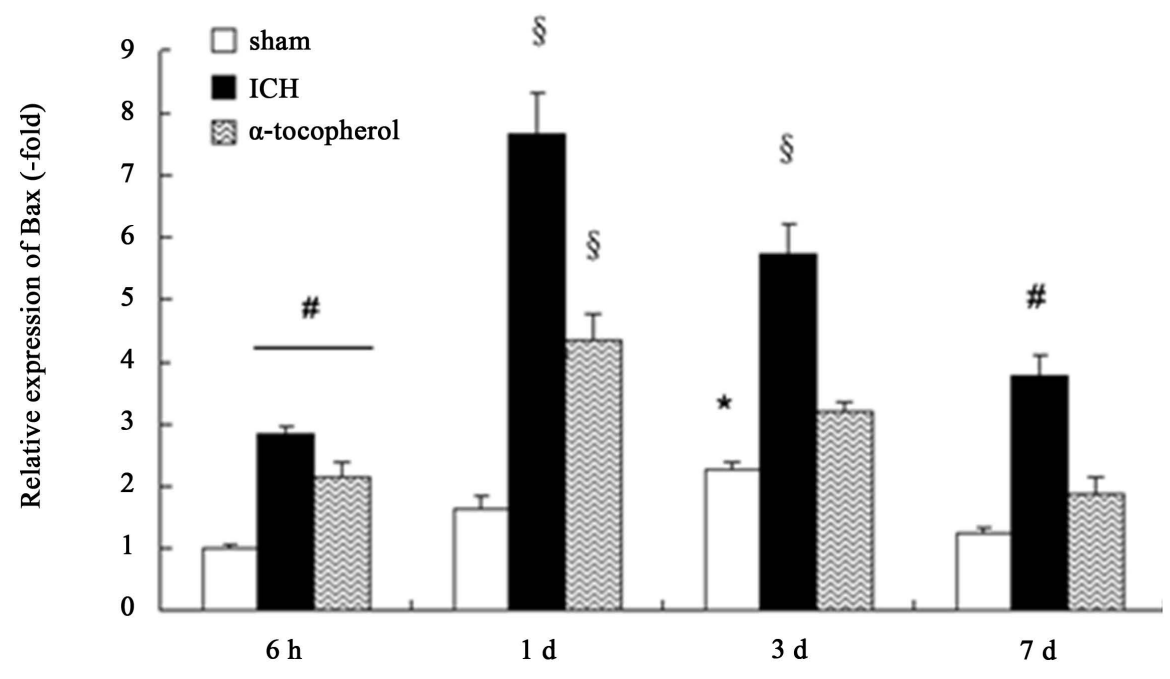

Figure 3. qRT-PCR showed the expression of Bax. Figure Labels: ${ }^{*} P<0.05$ versus Sham group $(6 \mathrm{~h}),{ }^{\#} p<0.05$ and ${ }^{\S} P<$ 0.01 versus Sham group, ${ }^{\#} P<0.05$ versus $\alpha$-tocopherolgroup $(7 \mathrm{~d})$.

Table 4. Bax expression in brain tissue surrounding the needle track in rats from different groups $(n=6)$.

\begin{tabular}{ccccc}
\hline Group & $6 \mathrm{~h}$ & $1 \mathrm{~d}$ & $3 \mathrm{~d}$ & $7 \mathrm{~d}$ \\
\hline Sham surgery group & $1.5 \pm 0.33$ & $2.49 \pm 0.29$ & $3.15 \pm 0.40$ & $1.88 \pm 0.44$ \\
ICH group & $4.48 \pm 0.39^{*}$ & $27.19 \pm 3.21^{*}$ & $20.84 \pm 1.90^{*}$ & $7.53 \pm 0.98^{*}$ \\
$\alpha$-tocopherol group & $4.09 \pm 0.48^{\#}$ & $14.15 \pm 0.45^{\mathbf{}}$ & $11.56 \pm 0.55^{\mathbf{}}$ & $3.48 \pm 0.40^{\mathbf{}}$ \\
F value & 187.496 & 518.667 & 694.711 & 233.902 \\
P value & 0.05 & $<0.01$ & $<0.01$ & $<0.01$ \\
\hline
\end{tabular}

Footnote: ${ }^{*}$ Bax expression in rats from the ICH group was significantly higher than in the sham surgery group, $P<0.01$; Bax expression in rats from the $\alpha$-tocopherol group was significantly lower than in the ICH group, ${ }^{\#} P<0.05,{ }^{\mathbf{\Lambda}} P<0.01$. 


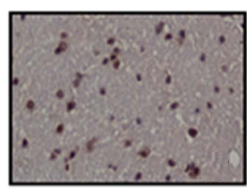

(a)

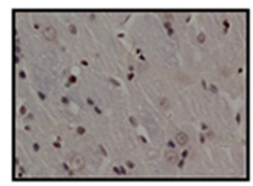

(e)

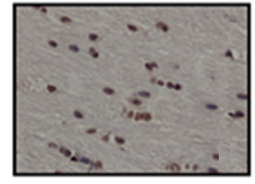

(i)

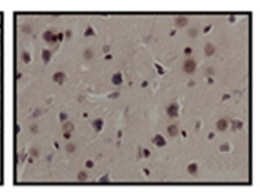

(b)

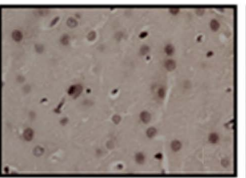

(f)

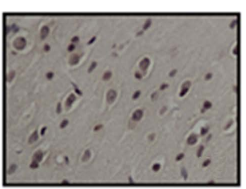

(c)

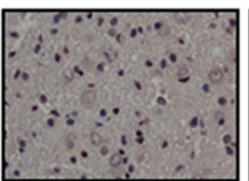

(g)

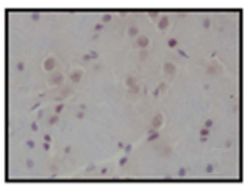

(d)

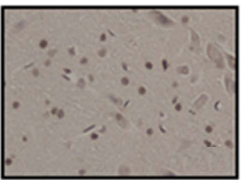

(h)

Figure 4. Bcl-2 expression in rat brain tissue. Figure Labels: All sections were observed under the same illumination intensity (4.0) and a $\times 400$ lens. (a)-(d): Bcl-2 positive staining in rat brain tissues; 6 h, $1 \mathrm{~d}, 3 \mathrm{~d}, 7 \mathrm{~d}$; ICH group. (e)-(h): Bcl-2 positive staining in rat brain tissues; 6 h, $1 \mathrm{~d}, 3 \mathrm{~d}, 7 \mathrm{~d}$; $\alpha$-tocopherol group. I: Bcl-2 positive staining in rat brain tissues, Sham surgery group.

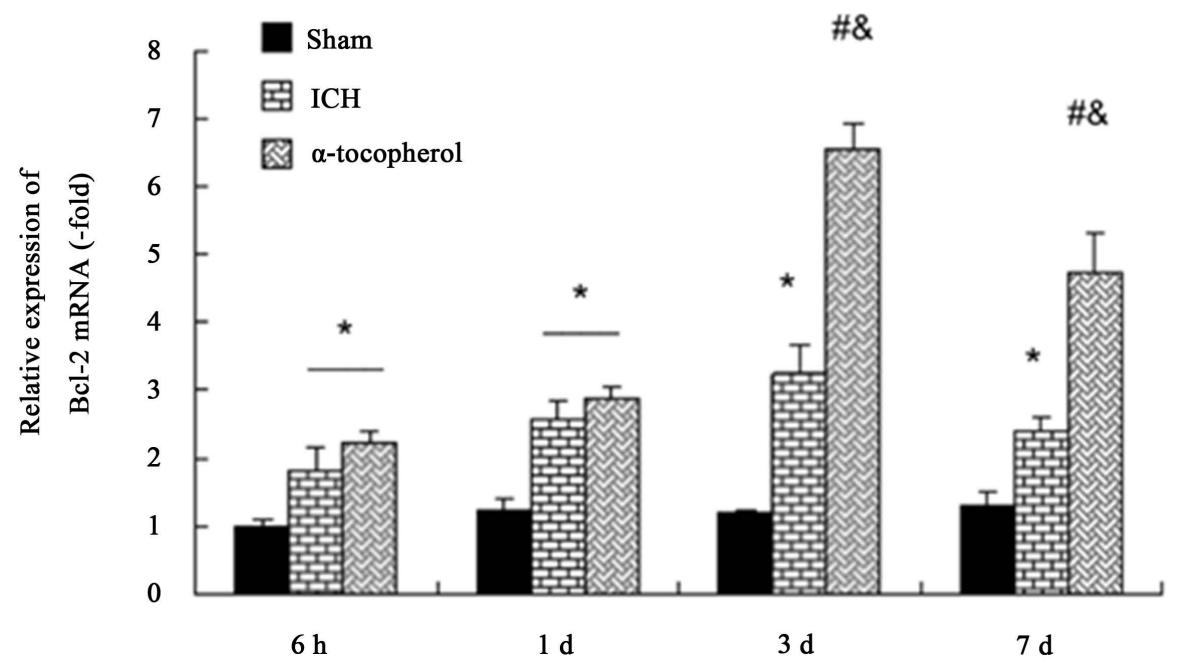

Figure 5. qRT-PCR showed the expression of Bcl-2. Figure Labels: ${ }^{*} P<0.05$ and ${ }^{\#} p<0.01$ versus Sham group, ${ }^{\circledR} P<0.05$ versus ICH group.

Table 5. Bcl-2 expression in brain tissue surrounding the needle track in rats from different groups $(\mathrm{n}=6)$.

\begin{tabular}{ccccc}
\hline Group & $6 \mathrm{~h}$ & $1 \mathrm{~d}$ & $3 \mathrm{~d}$ & $7 \mathrm{~d}$ \\
\hline Sham surgery group & $3.18 \pm 1.01$ & $3.37 \pm 1.14$ & $3.47 \pm 1.14$ & $3.35 \pm 1.24$ \\
ICH group & $13.48 \pm 1.20^{*}$ & $24.28 \pm 1.44^{*}$ & $43.99 \pm 3.87^{*}$ & $21.15 \pm 2.99^{*}$ \\
$\alpha$-tocopherol group & $15.20 \pm 1.45^{\#}$ & $32.51 \pm 4.02^{\#}$ & $97.56 \pm 9.95^{\#}$ & $56.64 \pm 5.7^{4 \#}$ \\
F value & 320.263 & 415.070 & 696.249 & 610.520 \\
P value & 0.01 & $<0.01$ & $<0.01$ & $<0.01$
\end{tabular}

Footnote: ${ }^{*} \mathrm{Bcl}-2$ expression in rats from the ICH group was significantly higher than in the sham surgery group, $P<0.01$; ${ }^{\#} \mathrm{Bcl}-2$ expression in rats from the $\alpha$-tocopherol group was significantly higher than in the ICH group, $P<0.01$. 
was caused by cerebral edema, ischemia, and hypoxia. As the cerebral edema, ischemia, and hypoxia became worse, cell apoptosis began, and secondary brain damage also became aggravated. At $3 \mathrm{~d}$, the functional neurological deficit of the rats was most severe. With the alleviation of the edema and neural cell compensation, the neurological function was later partially recovered. Clinically, most ICH patients also go through a process in which their neurological function gradually becomes more damaged, followed by a slow recovery. Patients with severe ICH die in a short amount of time due to severe brain damage. Cerebral edema and cell apoptosis play important roles in the functional neurological deficits that follow ICH [43] [44].

Studies have shown that vitamin E is a natural antioxidant and can counteract free radicals. Among all vitamin E compounds, $\alpha$-tocopherol has the most prominent antioxidative effect. In 2006, Castrol et al. found that $\alpha$-tocopherol showed a strong inhibitory effect on free radicals in in vitro culture of brain homogenate [45], Flanary reported that vitamin E could induce profound microglial proliferation [46]. This effect was even stronger than that of the well-known microglial mitogen granulocyte macrophage-colony stimulating factor.

The results of mNSS evaluation show that, rats in the $\alpha$-tocopherol treatment group had significantly lower mNSS scores than those in the ICH group. This suggests that $\alpha$-tocopherol can mitigate the functional neurological deficit in rats following ICH. Previous experiments have demonstrated that, after ICH, a large number of free radicals are produced, and these free radicals can induce the oxidative stress response. Studies have shown that when brain vascular smooth muscle cells are exposed to free radicals, their outward current increases, and membrane resistance decreases [47] [48]. The cells shrink and membrane vesicles appear. Eventually the cells die. In this way, free radicals may be one of the main causes of cerebrovascular spasm. Experiments have confirmed that the formation of free radicals and oxidative damage play important roles in acute central nervous system injury [49]. Active oxygen and active nitrogen are produced shortly after mechanical shock. One key component is the induction of lipid peroxidation. The formation of peroxide and lipid peroxidation cause irreversible damage to the function of lipids and the proteins of the cell membrane, leading to excitatory toxicity mediated by ionic equilibrium and glutamic acid, mitochondrial respiratory function failure, and microvascular damage.

More recent studies have shown than the cell membrane of neurons in the brain contains a relatively large amount of polyunsaturated fatty acid. The double bonds in an unsaturated fatty acid are prone to the effects of free radicals and lipid peroxidation reaction occurs, damaging the structure and function of the membrane [50]. Damages to the membrane function decrease ATP production. $\alpha$-tocopherol is oxidized easily. It is through reduction of oxygen radicals, inhibition of lipid peroxidation, and peroxidation of cells in the brain (including vascular endothelial cells and neurons) that the damage to the neural cells is alleviated and the normal function of neural cells can be recovered.

$\alpha$-tocopherol is a type of vitamin E. It has a relatively strong protective effect against oxygen free radicals, and studies have shown that $\alpha$-tocopherol can clear the free radicals that form after brain trauma. We deduced in our experiment that $\alpha$-tocopherol's ability to reduce the concentration of these free is the key element to its protective effects. This is why it can also inhibit peroxidation of neural cells, preserve the function of the cell membrane, counteract free-radical-induced damage to the blood-brain barrier, and so alleviate cerebral edema and brain tissue damage [40].

More and more studies have shown that cell apoptosis is heavily involved in secondary brain damage. At present, the Bcl-2 gene family and related proteins are receiving the most attention. Bcl-2 is an apoptosis-related gene, and it was the subject of many early investigations [51]. Bcl-2 proteins can be divided into two categories based on their functions. The proteins in the first category inhibit cell apoptosis. These include such proteins as Bcl-2, Mcl-1, and Bcl-xl. The proteins in the second category promote cell apoptosis. These mainly include such proteins as Bax, Bid, Bik, Bad, and Bcl-xs. Current studies on Bcl-2, Bax, and related proteins are relatively indepth [52] [53].

Our study demonstrated that after experimental ICH, notable amounts of cell apoptosis surrounding the hematoma were observed. This condition became aggravated from day 1 to day 3, after which it became less pronounced. This was accompanied by increased expression of Bcl-2 and Bax. Our results showed that in rats from the ICH group, Bax expression started early (6 h), peaking at $1 \mathrm{~d}$, and decreasing afterwards. At $7 \mathrm{~d}$ a small amount of Bax expression was still detectable. In rats from the $\alpha$-tocopherol group, Bax expression was significantly lower than in the ICH group at every point in time. Bcl-2 expression peaked relatively late but was still observable at $6 \mathrm{~h}$. It increased after $1 \mathrm{~d}$, peaking at $3 \mathrm{~d}$, and had been found to decrease at $7 \mathrm{~d}$. Tats from the $\alpha$ tocopherol group showed significantly higher Bcl-2 expression than the ICH control group at all points in time. 
The mechanisms underlying the anti-apoptosis effect of $\alpha$-tocopherol are as follows. Down-regulation of Bax expression in the brain tissue surrounding the lesion inhibits the release of cytochrome $\mathrm{C}$, but up-regulation of Bcl-2 expression changes the permeability of the mitochondrial membrane and the activation of cysteine. In this way, cell apoptosis after ICH is alleviated by reducing DNA damage. $A$-tocopherol clears free radicals, decreasing lipid peroxidation and preventing damage to the cell membrane, protecting its permeability being affected, reducing $\mathrm{Ca}^{2+}$ influx, and eventually alleviating cell apoptosis.

Our experimental results show that $\alpha$-tocopherol can decrease damage to the neural cells following ICH and significantly alleviate functional neurological deficit. $\alpha$-tocopherol can protect the brain after ICH by alleviating cerebral edema, up-regulate Bcl-2 expression, and down-regulate Bax expression, thus protecting the brain by reducing the rate of cell apoptosis after ICH. Although the details of the pathway still need further investigation, our results strongly suggest that $\alpha$-tocopherol may be an effective approach to the treatment of secondary brain damage.

\section{References}

[1] Jiang, B., Wang, W.Z., Chen, H., Hong, Z., Yang, Q.D., Wu, S.P., Du, X.L. and Bao, Q.J. (2006) Incidence and Trends of Stroke and Its Subtypes in China: Results from Three Large Cities. Stroke, 37, 63-68. http://dx.doi.org/10.1161/01.STR.0000194955.34820.78

[2] Van Asch, C.J., Luitse, M.J., Rinkel, G.J., van der Tweel, I., Algra, A. and Klijn, C.J. (2010) Incidence, Case Fatality, and Functional Outcome of Intracerebral Haemorrhage over Time, According to Age, Sex, and Ethnic Origin: A Systematic Review and Meta-Analysis. The Lancet Neurology, 9, 167-176. http://dx.doi.org/10.1016/S1474-4422(09)70340-0

[3] Weimar, C., Ziegler, A., Konig, I.R. and Diener, H.C. (2002) Predicting Functional Outcome and Survival after Acute Ischemic Stroke. Journal of Neurology, 249, 888-895. http://dx.doi.org/10.1007/s00415-002-0755-8

[4] Thomalla, G., Schwark, C., Sobesky, J., Bluhmki, E., Fiebach, J.B., et al. (2006) Outcome and Symptomatic Bleeding Complications of Intravenous Thrombolysis within 6 Hours in MRI-Selected Stroke Patients: Comparison of a German Multicenter Study with the Pooled Data of ATLANTIS, ECASS, and NINDS tPA Trials. Stroke, 37, 852-858. http://dx.doi.org/10.1161/01.STR.0000204120.79399.72

[5] Palm, F., Urbanek, C., Wolf, J., Buggle, F., Kleemann, T., Hennerici, M.G., Inselmann, G., Hagar, M., Safer, A., Becher, H. and Grau, A.J. (2012) Etiology, Risk Factors and Sex Differences in Ischemic Stroke in the Ludwigshafen Stroke Study, a Population-Based Stroke Registry. Cerebrovascular Diseases, 33, 69-75. http://dx.doi.org/10.1159/000333417

[6] Grysiewicz, R.A., Thomas, K. and Pandey, D.K. (2008) Epidemiology of Ischemic and Hemorrhagic Stroke: Incidence, Prevalence, Mortality, and Risk Factors. Neurologic Clinics, 26, 871-895. Review. http://dx.doi.org/10.1016/j.ncl.2008.07.003

[7] Lee, T.H., Hsu, W.C., Chen, C.J. and Chen, S.T. (2002) Etiologic Study of Young Ischemic Stroke in Taiwan. Stroke, 33, 1950-1955. http://dx.doi.org/10.1161/01.STR.0000021409.16314.16

[8] Hossmann, K.A. (2009) Pathophysiological Basis of Translational Stroke Research. Folia Neuropathologica, 47, 213-227.

[9] Ginsberg, M.D. (2009) Current Status of Neuroprotection for Cerebral Ischemia: Synoptic Overview. Stroke, 40, S111S114. http://dx.doi.org/10.1161/STROKEAHA.108.528877

[10] Rincon, F. and Mayer, S.A. (2010) Intracerebral Hemorrhage: Getting Ready for Effective Treatments. Current Opinion in Neurology, 23, 59-64. http://dx.doi.org/10.1097/wco.0b013e3283352c01

[11] Mould, W.A., Carhuapoma, J.R., Muschelli, J., Lane, K., Morgan, T.C., McBee, N.A., Bistran-Hall, A.J., Ullman, N.L., Vespa, P., Martin, N.A., Awad, I., Zuccarello, M. and Hanley, D.F., MISTIE Investigators (2013) Minimally Invasive Surgery plus Recombinant Tissue-Type Plasminogen Activator for Intracerebral Hemorrhage Evacuation Decreases Perihematomal Edema. Stroke, 44, 627-634. http://dx.doi.org/10.1161/STROKEAHA.111.000411

[12] Shen, H., Wu, X., Zhu, Y. and Sun, H. (2013) Intravenous Administration of Achyranthes bidentata Polypeptides Supports Recovery from Experimental Ischemic Stroke in Vivo. PLoS ONE, 8, e57055. http://dx.doi.org/10.1371/journal.pone.0057055

[13] Chang, Y.P. and Xie, Y.M. (2012) Overview of Pharmacoeconomic Studies on Traditional Chinese Medicines and Western Medicines in Treatment of Stroke. China Journal of Chinese Materia Medica, 37, 3509-3512. (In Chinese)

[14] Chen, J., Tang, Y.X., Liu, Y.M., Chen, J., Hu, X.Q., Liu, N., Wang, S.X., Zhang, Y., Zeng, W.G., Ni, H.J., Zhao, B., Chen, Y.F. and Tang, Z.P. (2012) Transplantation of Adipose-Derived Stem Cells Is Associated with Neural Differentiation and Functional Improvement in a Rat Model of Intracerebral Hemorrhage. CNS Neuroscience \& Therapeutics, 
18, 847-854. http://dx.doi.org/10.1111/j.1755-5949.2012.00382.x

[15] Chen, G.J. and Yang, M.S. (2013) The Effects of Calcium Channel Blockers in the Prevention of Stroke in Adults with Hypertension: A Meta-Analysis of Data from 273,543 Participants in 31 Randomized Controlled Trials. PLoS ONE, 8, e57854. http://dx.doi.org/10.1371/journal.pone.0057854

[16] Yu, Z.Z., Jiang, S.J., Bi, S., Li, J., Lei, D. and Sun, L.L. (2013) Relationship between Linguistic Functions and Cognitive Functions in a Clinical Study of Chinese Patients with Post-Stroke Aphasia. Chinese Medical Journal, 126, 12521256.

[17] Prabhakaran, S., Gupta, R., Ouyang, B., John, S., Temes, R.E., Mohammad, Y., Lee, V.H. and Bleck, T.P. (2010) Acute Brain Infarcts after Spontaneous Intracerebral Hemorrhage: A Diffusion-Weighted Imaging Study. Stroke, 41, 89-94. http://dx.doi.org/10.1161/STROKEAHA.109.566257

[18] Siddique, M.S., Fernandes, H.M., Wooldridge, T.D., Fenwick, J.D., Slomka, P. and Mendelow, A.D. (2002) Reversible Ischemia around Intracerebral Hemorrhage: A Single-Photon Emission Computerized Tomography Study. Journal of Neurosurgery, 96, 736-741. http://dx.doi.org/10.3171/jns.2002.96.4.0736

[19] Zazulia, A.R., Videen, T.O. and Powers, W.J. (2009) Transient Focal Increase in Perihematomal Glucose Metabolism after Acute Human Intracerebral Hemorrhage. Stroke, 40, 1638-1643. http://dx.doi.org/10.1161/STROKEAHA.108.536037

[20] Nau, R., Haase, S., Bunkowski, S. and Brück, W. (2002) Neuronal Apoptosis in the Dentate Gyrus in Humans with Subarachnoid Hemorrhage and Cerebral Hypoxia. Brain Pathology, 12, 329-336.

[21] Lin, C.L., Dumont, A.S., Su, Y.F., et al. (2009) Attenuation of Subarachnoid Hemorrhage-Induced Apoptotic Cell Death with 17 Beta-Estradiol: Laboratory Investigation. Journal of Neurosurgery, 111, 1014-1022. http://dx.doi.org/10.3171/2009.3.JNS081660

[22] Aronowski, J. and Zhao, X. (2011) Molecular Pathophysiology of Cerebral Hemorrhage: Secondary Brain Injury. Stroke, 42, 1781-1786. http://dx.doi.org/10.1161/STROKEAHA.110.596718

[23] Song, S., Hua, Y., Keep, R.F., Hoff, J.T. and Xi, G. (2007) A New Hippocampal Model for Examining Intracerebral Hemorrhage-Related Neuronal Death: Effects of Deferoxamine on Hemoglobin-Induced Neuronal Death. Stroke, 38, 2861-2863. http://dx.doi.org/10.1161/STROKEAHA.107.488015

[24] Ikram, M.A., Wieberdink, R.G. and Koudstaal, P.J. (2012) International Epidemiology of Intracerebral Hemorrhage. Current Atherosclerosis Reports, 14, 300-306. http://dx.doi.org/10.1007/s11883-012-0252-1

[25] Aggarwal, B.B., Sundaram, C., Prasad, S. and Kannappan, R. (2010) Tocotrienols, the Vitamin E of the 21st Century: Its Potential against Cancer and Other Chronic Diseases. Biochemical Pharmacology, 80, 1613-1631. http://dx.doi.org/10.1016/j.bcp.2010.07.043

[26] Quinn, P.J. (2012) The Effect of Tocopherol on the Structure and Permeability of Phosphatidylcholine Liposomes. Journal of Controlled Release, 160, 158-163. http://dx.doi.org/10.1016/j.jconrel.2011.12.029

[27] Christopher Min, K. (2007) Structure and Function of Alpha-Tocopherol Transfer Protein: Implications for Vitamin E Metabolism and AVED. Vitamins \& Hormones, 76, 23-43. http://dx.doi.org/10.1016/S0083-6729(07)76002-8

[28] Traber, M.G. (2006) Vitamin E. In: Shils, M.E., Shike, M., Ross, A.C., Caballero, B. and Cousins, R.J., Eds., Modern Nutrition in Health and Disease, Lippincott, Williams and Wilkins, Baltimore, 396-411.

[29] Muller, D.P. (2010) Vitamin E and Neurological Function. Molecular Nutrition \& Food Research, 54, 710-718. http://dx.doi.org/10.1002/mnfr.200900460

[30] Fish, W.H., Cohen, M., Franzek, D., Williams, J.M. and Lemons, J.A. (1990) Effect of Intramuscular Vitamin E on Mortality and Intracranial Hemorrhage in Neonates of 1000 Grams or Less. Pediatrics, 85, 578-584.

[31] Sjöholm, A., Berggren, P.O. and Cooney, R.V. (2000) Gamma-Tocopherol Partially Protects Insulin-Secreting Cells against Functional Inhibition by Nitric Oxide. Biochemical and Biophysical Research Communications, 277, 334-340. http://dx.doi.org/10.1006/bbrc.2000.3650

[32] Becvarova, I., Saker, K.E., Swecker Jr., W.S. and Troy, G.C. (2005) Peroxidative Protection of Parenteral Admixture by D- $\alpha$-Tocopherol. Veterinary Therapeutics, 6, 280-290.

[33] Hara, H., Kato, H. and Kogure, K. (1990) Protective Effect of $\alpha$-Tocopherol on Ischemic Neuronal Damage in the Gerbil Hippocampus. Brain Research, 510, 335-338. http://dx.doi.org/10.1016/0006-8993(90)91386-U

[34] Amin, K.A. and Hashem, K.S. (2012) Deltamethrin-Induced Oxidative Stress and Biochemical Changes in Tissues and Blood of Catfish (Clarias gariepinus): Antioxidant Defense and Role of $\alpha$-Tocopherol. BMC Veterinary Research, 8 , 45. http://dx.doi.org/10.1186/1746-6148-8-45

[35] Kapelusiak-Pielok, M., Adamczewska-Goncarzewicz, Z., Dorszewska, J. and Grochowalska, A. (2005) The Protective Action of $\alpha$-Tocopherol on the White Matter Lipids during Moderate Hypoxia in Rats. Folia Neuropathologica, 43, 103-108. 
[36] Rosenberg, G.A., Mun-Bryce, S., Wesley, M. and Kornfeld, M. (1990) Collagenase-Induced Intracerebral Hemorrhage in Rats. Stroke, 21, 801-807. http://dx.doi.org/10.1161/01.STR.21.5.801

[37] Paxinos, G. and Watson, C. (2004) The Rat Brain: In Stereotaxic Coordinates-The New Coronal Set. Elsevier Academic Press, Burlington.

[38] Bederson, J.B., Pitts, L.H., Tsuji, M., Nishimura, M.C., Davis, R.L. and Bartkowski, H. (1986) Rat Middle Cerebral Artery Occlusion: Evaluation of the Model and Development of a Neurologic Examination. Stroke, 17, 472-476. http://dx.doi.org/10.1161/01.STR.17.3.472

[39] Schallert, T., Kozlowski, D.A., Humm, J.L. and Cocke, R.R. (1997) Use-Dependent Structural Events in Recovery of Function. Advances in Neurology, 73, 229-238.

[40] Yang, J., Han, Y., Ye, W., Liu, F., Zhuang, K. and Wu, G. (2013) Alpha Tocopherol Treatment Reduces the Expression of Nogo-A and NgR in Rat Brain after Traumatic Brain Injury. Journal of Surgical Research, 182, e69-e77. http://dx.doi.org/10.1016/j.jss.2012.11.010

[41] Keep, R.F., Xi, G., Hua, Y. and Hoff, J.T. (2005) The Deleterious or Beneficial Effects of Different Agents in Intracerebral Hemorrhage: Think Big, Think Small, or Is Hematoma Size Important? Stroke, 36, 1594-1596. http://dx.doi.org/10.1161/01.STR.0000170701.41507.e1

[42] Wagner, K.R., Packard, B.A., Hall, C.L., Smulian, A.G., Linke, M.J., De Courten-Myers, G.M., Packard, L.M. and Hall, N.C. (2002) Protein Oxidation and Heme Oxygenase-1 Induction in Porcine White Matter Following Intracerebral Infusions of Whole Blood or Plasma. Developmental Neuroscience, 24, 154-160. http://dx.doi.org/10.1159/000065703

[43] Easton, A.S. (2012) Regulation of Permeability across the Blood-Brain Barrier. Advances in Experimental Medicine and Biology, 763, 1-19.

[44] Chen, S.F., Tsai, H.J., Hung, T.H., Chen, C.C., Lee, C.Y., Wu, C.H., Wang, P.Y. and Liao, N.C. (2012) Salidroside Improves Behavioral and Histological Outcomes and Reduces Apoptosis via PI3K/Akt Signaling after Experimental Traumatic Brain Injury. PLoS ONE, 7, e45763. http://dx.doi.org/10.1371/journal.pone.0045763

[45] Castro, I.A., Rogero, M.M., Junqueira, R.M. and Carrapeiro, M.M. (2006) Free Radical Scavenger and Antioxidant Capacity Correlation of Alpha-Tocopherol and Trolox Measured by Three in Vitro Methodologies. International Journal of Food Sciences and Nutrition, 57, 75-82. http://dx.doi.org/10.1080/09637480600656199

[46] Flanary, B.E. and Streit, W.J. (2006) Alpha-Tocopherol (Vitamin E) Induces Rapid, Nonsustained Proliferation in Cultured Rat Microglia. Glia, 53, 669-674. http://dx.doi.org/10.1002/glia.20313

[47] Frackowiak, J., Potempska, A. and Mazur-Kolecka, B. (2009) Formation of Amyloid-Beta Oligomers in Brain Vascular Smooth Muscle Cells Transiently Exposed to Iron-Induced Oxidative Stress. Acta Neuropathologica, 117, 557-567. http://dx.doi.org/10.1007/s00401-009-0497-0

[48] Stevanovic, D., Zhang, D., Blumenstein, A., Djuric, D. and Heinle, H. (2009) Effects of Hydroperoxides on Contractile Reactivity and Free Radical Production of Porcine Brain Arteries. General Physiology and Biophysics, 28, 93-97.

[49] Bains, M. and Hall, E.D. (2012) Antioxidant Therapies in Traumatic Brain and Spinal Cord Injury. Biochimica et Biophysica Acta, 1822, 675-684. http://dx.doi.org/10.1016/j.bbadis.2011.10.017

[50] Lauritzen, L., Hansen, H.S., Jørgensen, M.H. and Michaelsen, K.F. (2001) The Essentiality of Long Chain N-3 Fatty Acids in Relation to Development and Function of the Brain and Retina. Progress in Lipid Research, 40, 1-94. http://dx.doi.org/10.1016/S0163-7827(00)00017-5

[51] Yang, S.Y. and Xue, L. (2004) Human Neuronal Apoptosis Secondary to Traumatic Brain Injury and the Regulative Role of Apoptosis-Related Genes. Chinese Journal of Traumatology, 7, 159-164.

[52] Teles, A.V., Ureshino, R.P., Dorta, D.J., Lopes, G.S., Hsu, Y.T. and Smaili, S.S. (2008) Bcl-x(L) Inhibits Bax-Induced Alterations in Mitochondrial Respiration and Calcium Release. Neuroscience Letters, 442, 96-99. http://dx.doi.org/10.1016/j.neulet.2008.06.073

[53] Steckley, D., Karajgikar, M., Dale, L.B., Fuerth, B., Swan, P., Drummond-Main, C., Poulter, M.O., Ferguson, S.S., Strasser, A. and Cregan, S.P. (2007) Puma Is a Dominant Regulator of Oxidative Stress Induced Bax Activation and Neuronal Apoptosis. The Journal of Neuroscience, 27, 12989-12999. http://dx.doi.org/10.1523/JNEUROSCI.3400-07.2007 